\title{
Salicylate Intoxication and Influenza in Ferrets
}

\author{
CALVIN C. LINNEMANN, JR., ${ }^{(19)}$ KAZUHIRO UEDA, GEORGE HUG, ANN SCHAEFFER, \\ ANNETTE CLARK, AND GILBERT M. SCHIFF \\ Departments of Medicine, Pathology, and Pediatrics, University of Cincinnati College of Medicine, and The Children's \\ Hospital Medical Center, Cincinnati, Ohio, USA
}

\begin{abstract}
Summary
A model of salicylate intoxication was developed in ferrets to permit the evaluation of the interaction with viruses isolated from patients with Reye's syndrome. Salicylate intoxication produced a mild elevation of the serum glutamic oxaloacetic transaminase and fatty changes in the liver, but these changes differed from those seen in Reye's syndrome on light and electron microscopy. Salicylates were associated with decreased activity of hepatic phosphorylase and a slight depression of activity of ornithine transcarbamylase, a mitochondrial urea cycle enzyme. Infection with influenza viruses produced mild fatty changes in the liver, but did not significantly potentiate the effects of salicylate intoxication on the over-all mortality, the degree of fatty changes, or the hepatic enzymes. Influenza infection alone was not associated with decreased hepatic phosphorylase activity, but was associated with decreased activity of ornithine transcarbamylase. Influenza $A$ was isolated from the livers of two of four animals cultured in embryonated eggs.
\end{abstract}

\section{Speculation}

Because of its susceptibility to human influenza viruses, the ferret provides an animal model to evaluate potential toxic cofactors in the production of Reye's syndrome.

Reye's syndrome (RS), encephalopathy and fatty visceral changes, was defined in 1963 (12). Since then, numerous studies have reported the epidemiologic characteristics of the syndrome, and demonstrated the association with viral infections, particularly influenza viruses and varicella-zoster virus $(7,8)$. RS could represent one part of the spectrum of disease produced by the specific viruses involved, but it is difficult to explain some characteristics of the syndrome on infection alone. In particular, assuming that the apparent increase in the syndrome in recent years is a true observation, a new causal factor would seem to be involved (1). If RS was associated with only one virus, then the emergence of a new strain of virus could be postulated. However, the association of RS with several different viruses would require the development of new strains of each of these. A simpler hypothesis would be to implicate a co-factor in the production of the syndrome. Increasing exposure to the co-factor in recent decades could explain the increase in RS.

Epidemiologic studies have failed to identify a specific co-factor, but one thing which most children with RS have in common is the ingestion of aspirin during the prodrome (8). Evaluation of the role of aspirin in patients is difficult because of the widespread use of the drug and the fact that ingestion of aspirin decreases after the prodromal period due to vomiting. The latter may explain why most children with RS do not have serum salicylate levels in the toxic range at the time of hospitalization. Some investigators have not found a history of aspirin ingestion in many of their patients, but 53 of 56 patients with RS investigated by us had received salicylates (8). Frequently, this history had not been obtained at the time of hospitalization, but required a careful, detailed history by an investigator who was also familiar with the many preparations other than aspirin that contain salicylates. Therefore, salicylates seemed to be the best candidate for a cofactor, although other agents may be involved on occasion.

Animal models can provide an approach to diseases with a multifactorial etiology because the etiologic factors can be manipulated independently. Therefore, to test the hypothesis that acute salicylate intoxication interacts with viral infection to produce RS, a model of salicylate intoxication in ferrets was developed and utilized to evaluate the effect of virus plus salicylates. The ferret was selected for these studies because it is the only animal that could be infected easily with influenza viruses isolated from patients with RS, and it develops an illness similar to human influenza (15).

\section{MATERIALS AND METHODS}

\section{STUDY PLAN}

Four-month-old brown female ferrets (Mustela putorius furo) were divided into four groups: untreated controls, those given acetylsalicylic acid, those infected with influenza virus, and those receiving both salicylates and influenza virus. The animals were kept in individual cages; racks of cages with infected and uninfected animals were separated. The ferrets were anesthetized with ether in a dessicator jar before inoculation. Salicylates were started on day 1 of the study period. Acetylsalicylic acid (Aspirin, U.S.P., McKesson Laboratories) was mixed with water and inoculated through a plastic infant feeding tube into the stomach. The animals were given approximately $750 \mathrm{mg} / \mathrm{kg}$ twice a day for 4 days. This dose was selected because it resulted in the death of $50 \%$ of the animals. Two influenza viruses were used in the studies: 1) an influenza A/Hong Kong isolated from a patient with RS in 1972; and 2) an influenza B isolated from a patient with RS in 1974 (8). Animals were infected on day 1 of the study. One milliliter of virus containing greater than $10^{3.5} \mathrm{TCID}_{50}$ was inoculated into the nostrils with a tuberculin syringe. Food was removed from all animals after the first 2 days and the animals were killed on day 5 . Animals which died in the first $24 \mathrm{hr}$ were not included in the study. Forty-nine ferrets were studied, including 6 controls, 13 with salicylates, 22 infected with influenza A (14 of which also received salicylates), and 8 infected with influenza $B$ (5 of which also received salicylates).

\section{AUTOPSY PROCEDURE}

On day 5 of the study period, the animals were anesthetized and then killed by exsanguination. Animals which died before this time were autopsied as soon as possible after death. Serum collected at the time of exsanguination was used for the determination of salicylate levels, glucose, glutamic pyruvic transaminase, and glutamic oxaloacetic transaminase, which were measured by standard techniques (10). Specimens of liver, turbinates, lung, brain, heart, spleen, kidney, and muscle were collected. Tissues for viral isolation were placed in Eagle's minimum essential medium with Earle's balanced salt solution, albumin, and antibiotics, and frozen 
at $-70^{\circ}$ until tested; for light microscopy, in $10 \%$ phosphatebuffered neutral formalin; for electron microscopy, in cold phosphate-buffered $1 \%$ osmium tetroxide; and for the determination of hepatic enzymes, in liquid nitrogen.

\section{LABORATORY STUDIES}

Tissues for viral isolation were homogenized in iced Ten Broeck tissue grinders with 60 mesh alundum and $2 \mathrm{ml}$ serum-free media. The homogenates were inoculated into primary rhesus monkey kidney cell cultures, incubated in stationary racks at $35^{\circ}$, and tested for hemadsorption with guinea pig erythrocytes. Some liver specimens were also inoculated into embryonated eggs. For light microscopy, paraffin-imbedded tissue was stained with hematoxylin-eosin (H \& E) and periodic acid-Schiff stains, and frozen sections were stained with Sudan black and oil red O. For electron microscopy, thin sections of Epon-embedded tissues were stained with uranyl acetate and lead citrate, and examined with a Zeiss 9 $\mathrm{S}$ electron microscope.

Urea cycle enzymes, including ornithine transcarbamylase, carbamyl phosphate synthetase, arginase, and argininosuccinic lyase, and phosphorylase activities were determined on liver specimens by techniques used previously (3). For succinic dehydrogenase activity of hepatocytes, frozen sections were stained with the nitroblue tetrazolium method (9). The relative lipid content of the liver, expressed as the percentage of ether-extractable components to wet liver tissue, was determined by a modification of the technique of Folch et al. (6).

\section{RESULTS}

\section{CLINICAL AND LABORATORY FINDINGS}

The control animals remained healthy during the study. Three ferrets died on day 1 of the study as a result of cardiac puncture or anesthesia and were not included in the analysis. Six of 13 (46\%) ferrets given only salicylates died during the 5-day study period. Two died each day beginning on the 3rd study day. The animals became listless and tremulous, gradually progressing into coma. None of 11 ferrets infected with influenza viruses died. This included eight infected with influenza $A$, and three infected with influenza B. These animals developed a fever on day 2, but were afebrile on day 5. Some of the animals had rhinorrhea or sneezing, but the clinical manifestations were mild. Nineteen ferrets were infected with influenza viruses and given salicylates, including 14 infected with influenza $A$ and 5 with influenza $B$. Ten of the 19 $(53 \%)$ died. The animals in this group had a similar illness to those receiving just salicylates. Clinically, they appeared sicker, but the over-all mortality was not significantly increased. The majority of deaths occurred on day 4 of the study. On day 5, approximately $18 \mathrm{hr}$ after the last dose of salicylates, the mean salicylate level was $33.6 \mathrm{mg} \%$. The mean blood glucose level was $102.5 \mathrm{mg} \%$ for the control animals, $106.0 \mathrm{mg} \%$ for animals receiving salicylates, and $100.8 \mathrm{mg} \%$ for those receiving just virus. None of the animals became hypoglycemic. There was considerable variation in the serum transaminases among individual animals, but ferrets receiving salicylates had a slightly higher mean SGOT, $130.2 \mathrm{mU} / \mathrm{ml}$, than controls, $93.7 \mathrm{mU} / \mathrm{ml}$, or infected animals, $114 \mathrm{mU} / \mathrm{ml}$. These differences are not significant, but elevated transaminases correlated with the most severe fatty changes at autopsy. The mean SGOT in those with severe fatty changes was $228 \mathrm{mU} / \mathrm{ml}$ $(P<0.05$, Student's $t$-test $)$.

Influenza virus was recovered from the turbinates in 28 of 29 animals cultured, and from the lungs in 18 of 23 . Recovery of virus was similar in those receiving salicylates and those not receiving salicylates. There was no difference between influenza $A$ and $B$ regarding the rate of recovery of the virus from the lung specimens. Virus was recovered in cell culture from the brain of one animal, but all other cultures of organs were negative. Because of a recent report of the isolation of influenza virus from the livers of infected ferrets by egg inoculation, the livers of four animals infected with influenza A and five with influenza B were inoculated into embryonated eggs (16). Influenza virus was recovered from two of the four livers of animals infected with influenza $A$, but none of the livers from animals with influenza B. Cultures of uninfected animals were negative.

\section{PATHOLOGIC FINDINGS}

Changes recognizable by gross examination were limited to the liver. The liver was diffusely pale yellow when severe fatty changes were present, and showed reticulated yellowish markings when mild periportal fatty changes were present. On light microscopy, the livers of normal ferrets showed an abundant glycogen content, and fat droplets were present in the extracellular spaces and Kupffer cells, but not in hepatocytes. When normal ferrets were fasted and anesthetized with ether, there was some decrease in glycogen content and minimal fatty changes in hepatocytes. Virusinfected animals developed mild periportal fatty changes, characterized by medium-size vacuoles. Ferrets receiving salicylates with or without virus developed moderate to severe fatty changes which were characterized by medium-size vacuoles and which were most severe in the periportal areas (Figure 1). Some microvacuolar changes were present in the centrilobular areas. There was no significant difference between those animals receiving only salicylates and those also infected with influenza virus. There were no differences between influenza A and B. Animals which died early ( 3 to 4 days) tended to have more microvacuolar fat, whereas those which survived to day 5 had larger fat vacuoles. Histochemical staining indicated that the fat was triglyceride. Glycogen depletion paralleled the severity of the fatty changes. There was no evidence of cellular necrosis or inflammation. The fat content of the liver (ether-extractable substance), as reflected in the percent of the wet weight, increased directly with the increasing serum salicylate level.

Electron microscopy of the liver did not reveal consistent changes. In some animals receiving salicylates with or without influenza virus, there was enlargement and pleomorphism of the mitochondria with loss of the dense bodies. When present, these changes were not homogeneous throughout the liver, but present only in periportal hepatocytes.

Fatty changes were also seen in the myocardium in animals receiving salicylates and/or virus and paralleled those in the liver. The only changes in the brain were selective neuronal necrosis compatible with anoxic injury. The lungs of 21 ferrets infected with influenza were examined and 11 showed a focal acute necrotizing broncho-bronchiolitis. This occurred in animals infected with both influenza $A$ and influenza B, was not more frequent in those receiving salicylates, and did not occur in uninfected animals.

\section{HEPATIC ENZYMES}

Salicylate intoxication was associated with decreased phosphorylase and ornithine transcarbamylase activities (Table 1). Other urea cycle enzymes and succinic dehydrogenase activity were not affected. Phosphorylase activity was not depressed in animals with influenza alone, but urea cycle enzymes were. Ornithine transcarbamylase activity was depressed slightly in animals with influenza A, comparable to the effect of salicylate intoxication. Animals with influenza B had a greater depression of ornithine transcarbamylase activity, and some depression of extramitochondrial urea cycle enzymes, including arginase and argininosuccinic lyase. Carbamyl phosphate synthetase was normal in infected and also salicylate-treated animals, and so was succinic dehydrogenase activity as examined histochemically.

\section{DISCUSSION}

The hepatic lesions in patients with RS have been reported in detail $(2,3,13)$. Light microscopy shows diffuse microvacuolar fatty changes with somewhat larger lipid droplets in the periportal zone, and varying degrees of glycogen depletion, most marked at 

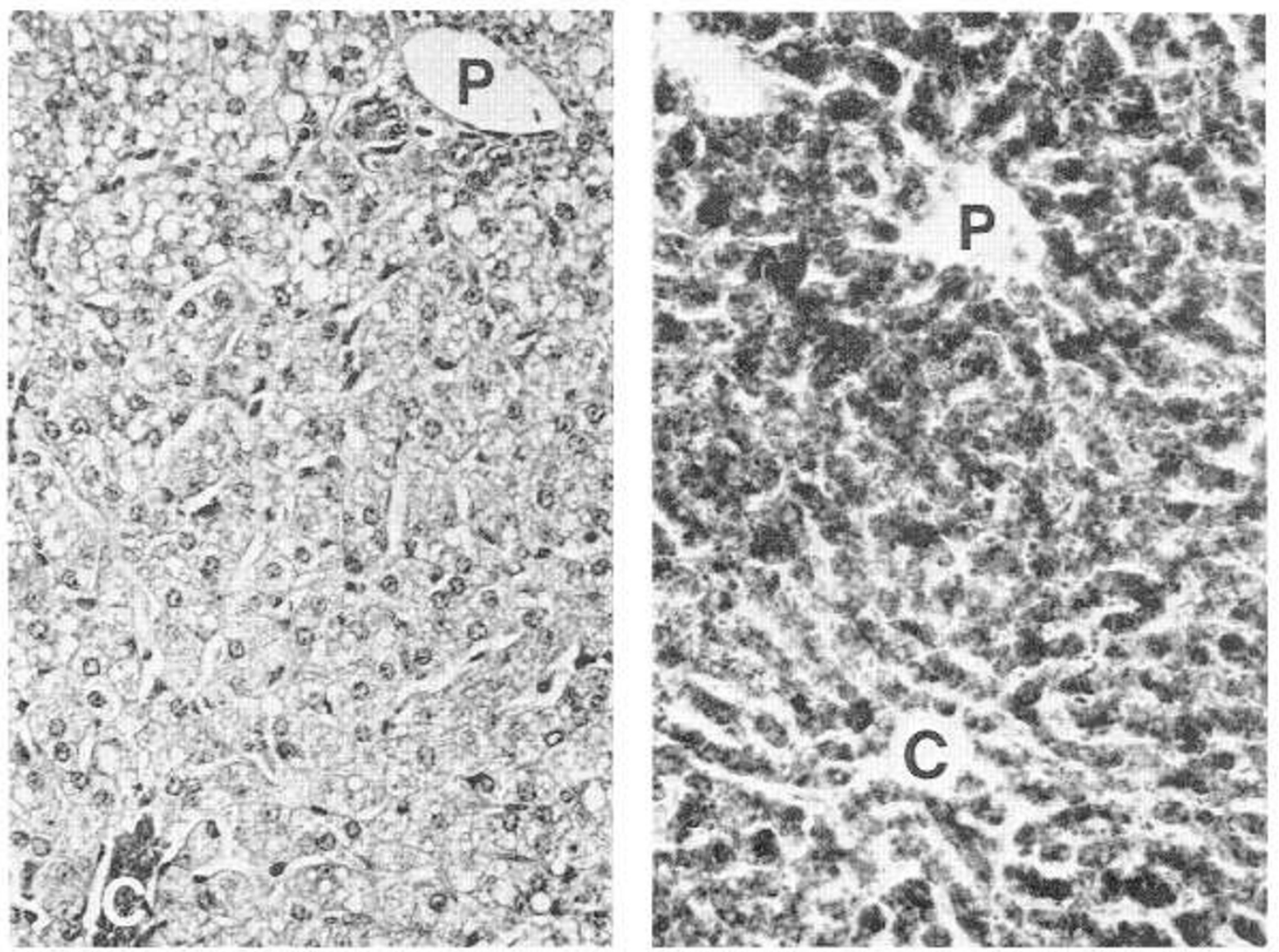

Fig. 1. Microphotographs of the liver from an influenza-aspirin treated ferret (left, H \& E stain, $\times 250$; right, Sudan black stain, $\times 160$ ). P, portal zones; $\mathrm{C}$, central veins. There is diffuse fatty change: medium-size vacuolar in the periportal zones and microvacuolar in the centrilobular areas.

Table 1. Results of hepatic enzymes measured in ferret livers by study group, including carbamyl phosphate synthetase (CPS), ornithine transcarbamylase $(O T C)$, arginase $(A R G)$, argininosuccinic lyase $(A S L)$, and phosphorylase (PHOS)

\begin{tabular}{|c|c|c|c|c|c|}
\hline $\begin{array}{c}\text { Study group } \\
\text { (no.) }\end{array}$ & \multicolumn{5}{|c|}{ Hepatic enzymes } \\
\hline \multirow[t]{2}{*}{ Salicylates (6) } & 59.2 & $1188.8^{1}$ & 1933.1 & 55.9 & $34.6^{2}$ \\
\hline & \pm 15.0 & \pm 396.8 & \pm 197.3 & \pm 10.3 & \pm 10.3 \\
\hline \multicolumn{6}{|l|}{ Influenza A } \\
\hline \multirow[t]{2}{*}{ Virus only (2) } & 46.5 & $1248.4^{1}$ & 1944.8 & 49.6 & 42.0 \\
\hline & \pm 10.5 & \pm 68.5 & \pm 241.3 & \pm 0.64 & \pm 7.6 \\
\hline With salicylates (6) & 56.3 & $1073.0^{1}$ & 1608.1 & 46.4 & $25.9^{2}$ \\
\hline Virus only (3) & \pm 5.8 & \pm 157.2 & \pm 567.3 & \pm 5.2 & \pm 8.0 \\
\hline \multirow[t]{2}{*}{ With salicylates (3) } & 64.7 & $772.0^{2}$ & $1373.9^{1}$ & $38.8^{1}$ & $26.2^{2}$ \\
\hline & \pm 19.8 & \pm 125.9 & \pm 70.4 & \pm 4.6 & \pm 5.0 \\
\hline \multirow[t]{2}{*}{ Combined (6) } & 61.7 & $814.2^{2}$ & $1550.2^{1}$ & $42.2^{1}$ & 39.7 \\
\hline & \pm 13.4 & \pm 135.5 & \pm 409.9 & \pm 5.8 & \pm 16.0 \\
\hline
\end{tabular}

\footnotetext{
${ }^{1} P<0.05$

${ }^{2} P<0.01$
} 
the periphery of the hepatic lobule (2). On electron microscopy, there is alteration of the mitochondria with rarefication of the matrix space, loss of mitochondrial dense bodies, and mitochondrial pleomorphism (13). Measurement of hepatic enzymes has shown that the activity of carbamyl phosphate synthetase, ornithine transcarbamylase, and succinic dehydrogenase is reduced $(2,3)$. In one study of 11 patients with severe RS, all patients who were studied within $72 \mathrm{hr}$ of the onset of illness had significantly reduced activity of carbamyl phosphate synthetase and ornithine transcarbamylase (3). These combined studies provide a description of the morphologic as well as enzymatic abnormalities of RS which are believed to be characteristic for the syndrome.

In the present study, salicylates did produce fatty changes in the livers of the experimental animals, but the fat occurred predominantly in medium-size vacuoles and was most severe in the periportal areas. Microvacuolar changes were present occasionally. in animals which died on day 3 or 4 of the study. This pattern differs from the diffuse microvacuolar changes reported in RS (2). In addition, there was no reduction of hepatic succinic dehydrogenase activity, which would be an expected finding in patients with RS (2). The hepatic lesions in salicylate intoxication in humans have not been clearly defined, but "fatty infiltration and fatty degeneration" of the liver have been reported with acute intoxication (17). However, these changes have not been found in recent descriptions of "aspirin hepatitis" in patients on therapeutic doses of salicylates (14). It is of interest that salicylate intoxication did depress the hepatic phosphorylase activity in the ferrets, as has been found in RS (G. Hug, unreported observations). Viral infection alone did not produce marked fatty changes although limited studies indicate that virus reaches the liver during acute infection in the ferret (16). Infection did appear to affect urea cycle enzymes. A previous report of influenza infection of mice showed a slight depression of urea cycle enzymes which was interpreted as a nonspecific effect of severe illness (11). The virus used in that study had been passaged repeatedly in mice and produced a high mortality in the study animals.

Salicylates were started on the same day as the viral infection in the present study because most children with RS do not receive aspirin until they are infected. Occasionally, RS develops in children who have been receiving salicylates for a long period of time because of other illnesses such as juvenile rheumatoid arthritis (8). Chronic salicylate ingestion would be difficult to maintain in the ferret model, but parenteral administration of sodium salicylate could be used. This was not evaluated in the present study because chronic intoxication would explain only a very few of the cases of RS. However, variable host responses to salicylates could be an important factor which might not be present in an animal model. One host variable is age. The average life span of a ferret is 5 to 6 years. Four-month-old ferrets were used in the study. Because RS is a disease of older infants and children, even younger ferrets might be appropriate for further study. Ferrets are weaned by 6 to 7 weeks; therefore, so 2-month-old animals could be used.

Although this study did not produce a model of RS, it does illustrate the criteria which should be fulfilled if such a model is developed. The demonstration of diffuse microvacuolar fatty changes in the liver on light microscopy must be supplemented by electron microscopy to show changes in the mitochondria and should include the evaluation of hepatic enzymes to show changes in the activity of mitochondrial urea cycle enzymes. A mouse model has been reported in which encephalomyocarditis virus together with pesticides or pesticide components produced fatty changes in the liver $(4,5)$. However, electron microscopy and enzyme determinations were not done. The presence of a fatty liver on light microscopy is not sufficient to make a diagnosis of RS (13). Another important consideration in the development of animal models involving viral infections is the variation in viral strains. In the present study, low passaged isolates from patients with biopsy-proven RS were used. Different strains or higher passages of the same strains may produce different results.

\section{REFERENCES AND NOTES}

I. Bove, K. E.: In: J. D. Pollack: Reye's Snydrome, p. 93 (Grune \& Stratton, New York, 1974).

2. Bove, K. E., McAdams, A. J., Partin, J. C., et al.: The hepatic lesion in Reye's syndrome. Gastroenterology, 69: 685 (1976).

3. Brown, T., Hug, G., Landky, L., et al.: Transiently reduced activity of carbamyl phosphate synthetase and ornithine transcarbamylase in liver of childhren with Reye's syndrome: N. Engl. J. Med., 294: 861 (1976).

4. Crocker, J. F. S., Ozere, R. L., Safe, S. H., et al.: Lethal interaction of ubiquitous insecticide carriers with virus. Science (Wash., D. C.), 192: 1331 (1976)

5. Crocker, J. F. S., Rozee, K. R., Ozere, R. L., et al.: Insecticide and viral interaction as a cause of fatty visceral changes and encephalopathy in the mouse. Lancet, II: 22 (1974)

6. Folch, J., Lees, M., and Stanley, G. H. S.: A simple method for the isolation and purification of total lipides from animal tissues. J. Biol. Chem., 226: 497 (1957).

7. Linnemann, C. C., Jr., Shea, L., Kauffman, C. A., et al.: Association of Reye's syndrome with viral infection. Lancet, II: 179 (1974).

8. Linnemann, C. C. Jr., Shea, L., Partin, J. C., et al.: Reye's syndrome: Epidemiologic and viral studies, 1963-1974. Am J. Epidemiol., 10I: 517 (1975).

9. Nachlas, M. M., Tsou, K. C., Souza, E., et al.: Cytochemical demonstration of succinic dehydrogenase by the use of a new p-nitrophenyl substituted ditetrazole. J. Histochem. Cytochem., 5: 420 (1957).

10. Natelson, S.: Techniques of Clinical Chemissry, Ed. 3 (Charles C Thomas, Springfield, IL, 1971)

11. Pierson, D. V., Knight, P., Hansard, P., et al.: Hepatic carbamyl phosphate synthetase and ornithine transcarbamylase in mouse influenza $A$ and influenza B infection. Proc. Soc. Exp. Biol. Med., 152: 67 (1976).

12. Reye, R. D., Morgan, G., and Baral, J.: Encephalopathy and fatty degeneration of the viscera. A disease entity in childhood. Lancet, II: 749 (1963).

13. Schubert, W. K., Partin, J. C., and Partin, J. S.: In: H. Poppes and F. Schaffner: Progress in Liver Disease, Ed. 4, p. 489 (Grune \& Stratton, New York, 1972).

14. Seaman, W. E., Ishak, K. F.; and Plotz, P. H.: Aspirin-induced hepatotoxicity in patients with systemic lupus erythematosus. Ann. Intern. Med., 80: 1 (1974).

15. Smith, W., Andrews, C. H., and Laidlaw, P. P.: A virus obtained from influenza patients. Lancet, II: 66 (1933).

16. Toms, G. L., Bird, R. A., Kingsman, S. M., et al.: The behaviour in ferrets of two closely related clones of influenza virus of differing virulence for man. Br. $\mathbf{J}$. Exp. Pathol., 57: 37 (1976).

17. Troll, M. M., and Menten, M. L.: Salicylate poisoning. Am. J. Dis. Child., 69: 37 (1945).

I8. This research was supported in part by NIH Grants RR05535 and RR00123, and The Children's Hospital Research Foundation.

19. Requests for reprints should be addressed to: C. C. Linnemann, Jr., M.D., Infectious Disease Division, University of Cincinnati Medical Center, Cincinnati, OH 45267 (USA)

20. Received for publication January 3, 1978.

21. Accepted for publication March 2, 1978. 